\title{
TU/e EN⿴HONE

\section{Precise ion energy control with tailored waveform biasing for atomic scale processing}

\section{Citation for published version (APA):}

Faraz, T., Verstappen, Y. G. P., Verheijen, M. A., Chittock, N., Escandon Lopez, J., Heijdra, E., van Gennip, W. J. H., Kessels, W. M. M., \& Mackus, A. J. M. (2020). Precise ion energy control with tailored waveform biasing for atomic scale processing. Journal of Applied Physics, 128(21), [213301]. https://doi.org/10.1063/5.0028033

\section{Document license:}

TAVERNE

DOI:

$10.1063 / 5.0028033$

Document status and date:

Published: 07/12/2020

\section{Document Version:}

Publisher's PDF, also known as Version of Record (includes final page, issue and volume numbers)

\section{Please check the document version of this publication:}

- A submitted manuscript is the version of the article upon submission and before peer-review. There can be important differences between the submitted version and the official published version of record. People interested in the research are advised to contact the author for the final version of the publication, or visit the $\mathrm{DOI}$ to the publisher's website.

- The final author version and the galley proof are versions of the publication after peer review.

- The final published version features the final layout of the paper including the volume, issue and page numbers.

Link to publication

\section{General rights}

Copyright and moral rights for the publications made accessible in the public portal are retained by the authors and/or other copyright owners and it is a condition of accessing publications that users recognise and abide by the legal requirements associated with these rights.

- Users may download and print one copy of any publication from the public portal for the purpose of private study or research.

- You may not further distribute the material or use it for any profit-making activity or commercial gain

- You may freely distribute the URL identifying the publication in the public portal.

If the publication is distributed under the terms of Article 25fa of the Dutch Copyright Act, indicated by the "Taverne" license above, please follow below link for the End User Agreement:

www.tue.nl/taverne

Take down policy

If you believe that this document breaches copyright please contact us at:

openaccess@tue.nl

providing details and we will investigate your claim. 


\section{Precise ion energy control with tailored waveform biasing for atomic scale processing}

Cite as: J. Appl. Phys. 128, 213301 (2020); https://doi.org/10.1063/5.0028033

Submitted: 02 September 2020 . Accepted: 17 November 2020 . Published Online: 07 December 2020

(D) Tahsin Faraz, Yuri G. P. Verstappen, (D) Marcel A. Verheijen, (D) Nicholas J. Chittock, Javier Escandon Lopez, Erik Heijdra, Wouter J. H. van Gennip, (Dilhelmus M. M. Kessels, and (iD) Adriaan J. M. Mackus

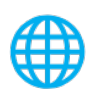

\section{ARTICLES YOU MAY BE INTERESTED IN}

Overview of atomic layer etching in the semiconductor industry

Journal of Vacuum Science \& Technology A 33, 020802 (2015); https://

doi.org/10.1116/1.4913379

Isotropic plasma atomic layer etching of $\mathrm{Al}_{2} \mathrm{O}_{3}$ using a fluorine containing plasma and $\mathrm{Al}\left(\mathrm{CH}_{3}\right)_{3}$

Applied Physics Letters 117, 162107 (2020); https://doi.org/10.1063/5.0022531

Status and prospects of plasma-assisted atomic layer deposition

Journal of Vacuum Science \& Technology A 37, 030902 (2019); https://

doi.org/10.1116/1.5088582

Challenge us.

What are your needs for periodic signal detection?

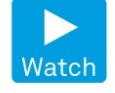

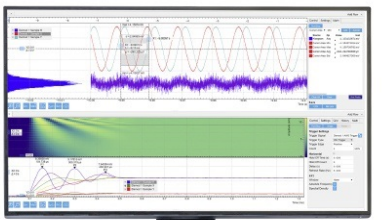

-
Zurich

- Instruments 


\title{
Precise ion energy control with tailored waveform biasing for atomic scale processing
}

\author{
Cite as: J. Appl. Phys. 128, 213301 (2020); doi: 10.1063/5.0028033 \\ Submitted: 2 September 2020 . Accepted: 17 November 2020 . \\ Published Online: 7 December 2020
}

Tahsin Faraz, ${ }^{1}$ (D) Yuri G. P. Verstappen, ${ }^{7}$ Marcel A. Verheijen, ${ }^{1,2}$ (D) Nicholas J. Chittock, ${ }^{7}$ (D) Javier Escandon Lopez, ${ }^{3}$ Erik Heijdra, ${ }^{3}$ Wouter J. H. van Gennip, ${ }^{3}$ Wilhelmus M. M. Kessels, ${ }^{1}$ (D) and Adriaan J. M. Mackus ${ }^{1, a)}$ (D)

\begin{abstract}
AFFILIATIONS
${ }^{1}$ Department of Applied Physics, Eindhoven University of Technology, P. O. Box 513, 5600 MB Eindhoven, The Netherlands

${ }^{2}$ Eurofins Materials Science Netherlands, High Tech Campus 11, 5656 AE Eindhoven, The Netherlands

${ }^{3}$ Prodrive Technologies B.V., Science Park Eindhoven 5501, 5692 EM Son, The Netherlands
\end{abstract}

a) Author to whom correspondence should be addressed: A.J.M.Mackus@tue.nl

\begin{abstract}
Anisotropic plasma-enhanced atomic layer etching (ALE) requires directional ions with a well-defined ion energy to remove materials in a highly selective and self-limiting fashion. In many plasma etching systems, the ion energy is controlled using radio-frequency (13.56 MHz) sinusoidal waveform biasing. However, this yields ions with a broad energy distribution, while also inducing electron heating mechanisms that can affect the ion flux. In this work, we report on precise ion energy control-independent of the ion flux-using low-frequency (LF: $100 \mathrm{kHz}$ ) tailored bias voltage waveforms in a commercial remote plasma reactor. A prototype LF bias generator has been used to apply tailored waveforms consisting of a positive voltage pulse and a negative linear voltage ramp. These waveforms yielded ions having narrow energy distributions $\left(7 \pm 1 \mathrm{eV}\right.$ full-width-at-half-maximum) measured on dielectric $\mathrm{SiO}_{2}$ substrates for ion energies up to $200 \mathrm{eV}$ in collisionless Ar plasmas. The mono-energetic ions were used to etch $\mathrm{SiO}_{2}$ thin films by physical sputtering. In these sputter etch experiments, the ability to accurately control the ion energy in the $<100 \mathrm{eV}$ range is demonstrated to allow for a more precise determination of sputter thresholds, which serve as valuable input for the design of novel ALE chemistries. The feasibility of performing anisotropic plasma etching using LF tailored waveform biasing was established by etching a $\mathrm{SiO}_{2}$ layer on a $3 \mathrm{D}$ trench nanostructure. The potential merits of this technique for the field of atomic scale processing are discussed.
\end{abstract}

Published under license by AIP Publishing. https://doi.org/10.1063/5.0028033

\section{INTRODUCTION}

As critical dimensions in semiconductor devices approach a few nanometers, there is an urgent need for atomic scale processing techniques offering high selectivity and precise thickness control. ${ }^{1,2}$ Atomic layer etching (ALE) is one such technique that enables material removal with atomic scale precision. ${ }^{3,4}$ It consists of two or more sequential surface reaction steps where at least one of the steps is self-limiting in nature. At its core, etching means the removal of atoms from any given material by bond dissociation, which involves overcoming an energy barrier called the binding energy. ${ }^{3,5}$ In the initial step of an ALE cycle, the aim is to weaken the binding energy between the surface and bulk atoms of a target material so that it becomes easier to remove the surface atoms. This is achieved by exposing the material to reactive species (e.g., plasma radicals, precursor gas molecules, etc.) that form a modified surface region preferably through self-limiting chemical reactions. $^{3,4,6}$ In anisotropic plasma-enhanced ALE, the modified surface region is removed in the next step of the ALE cycle using energetic and directional ions. ${ }^{3,4}$ Self-limitation is ensured by operating in a process window, where the incident ions have enough energy to remove the modified surface region but not the underlying bulk. Energetic ions dissociate the relatively weak bonds between the modified surface and the underlying bulk, while simultaneously inducing chemical reactions that create volatile reaction products. Removal of materials in this manner has been termed as chemical sputtering (or chemically enhanced etching), ${ }^{7,8}$ whereby the impinging ions have an energy above a threshold known as the chemical sputter etch threshold, as illustrated in Fig. 1(a). When the ion energy is high enough to break bonds in the unmodified bulk, atoms are physically displaced from their equilibrium positions and can eventually be ejected from the target material. This 


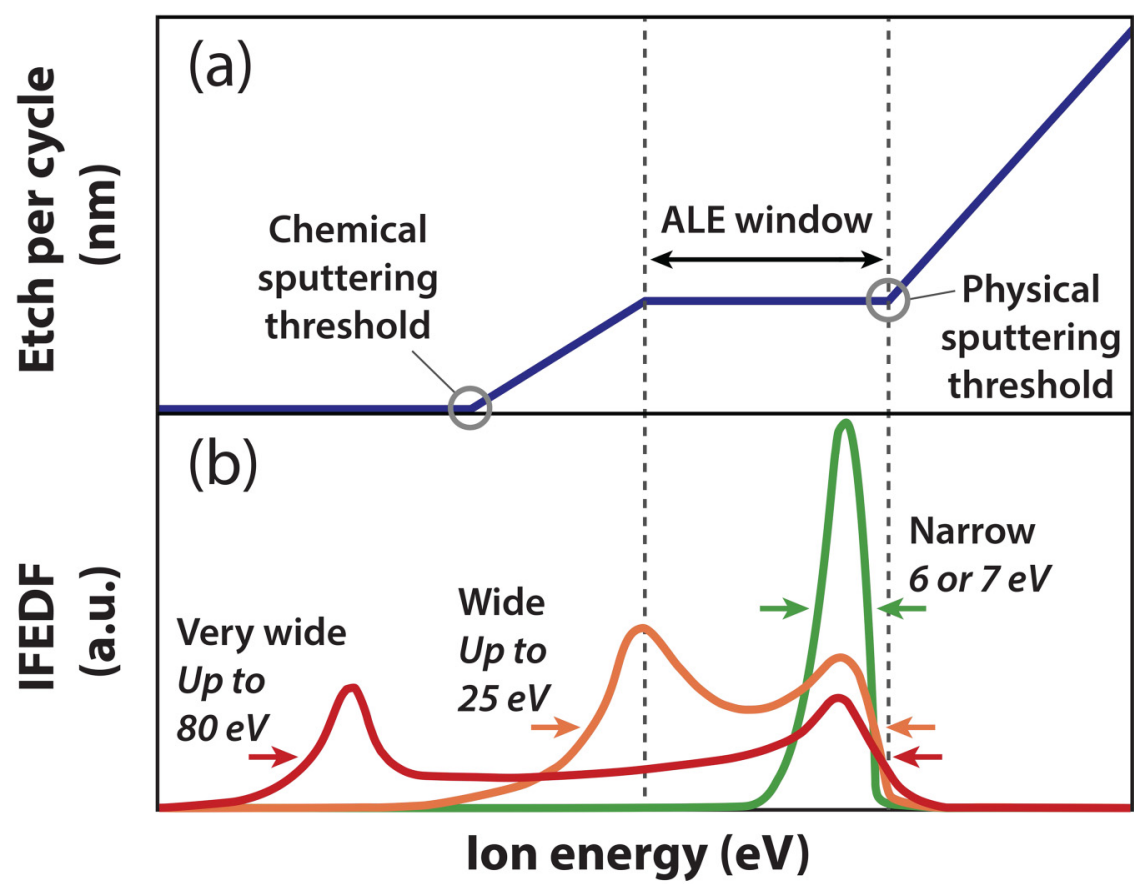

Bias waveforms

LF sinusoidal

RF sinusoidal LF tailored

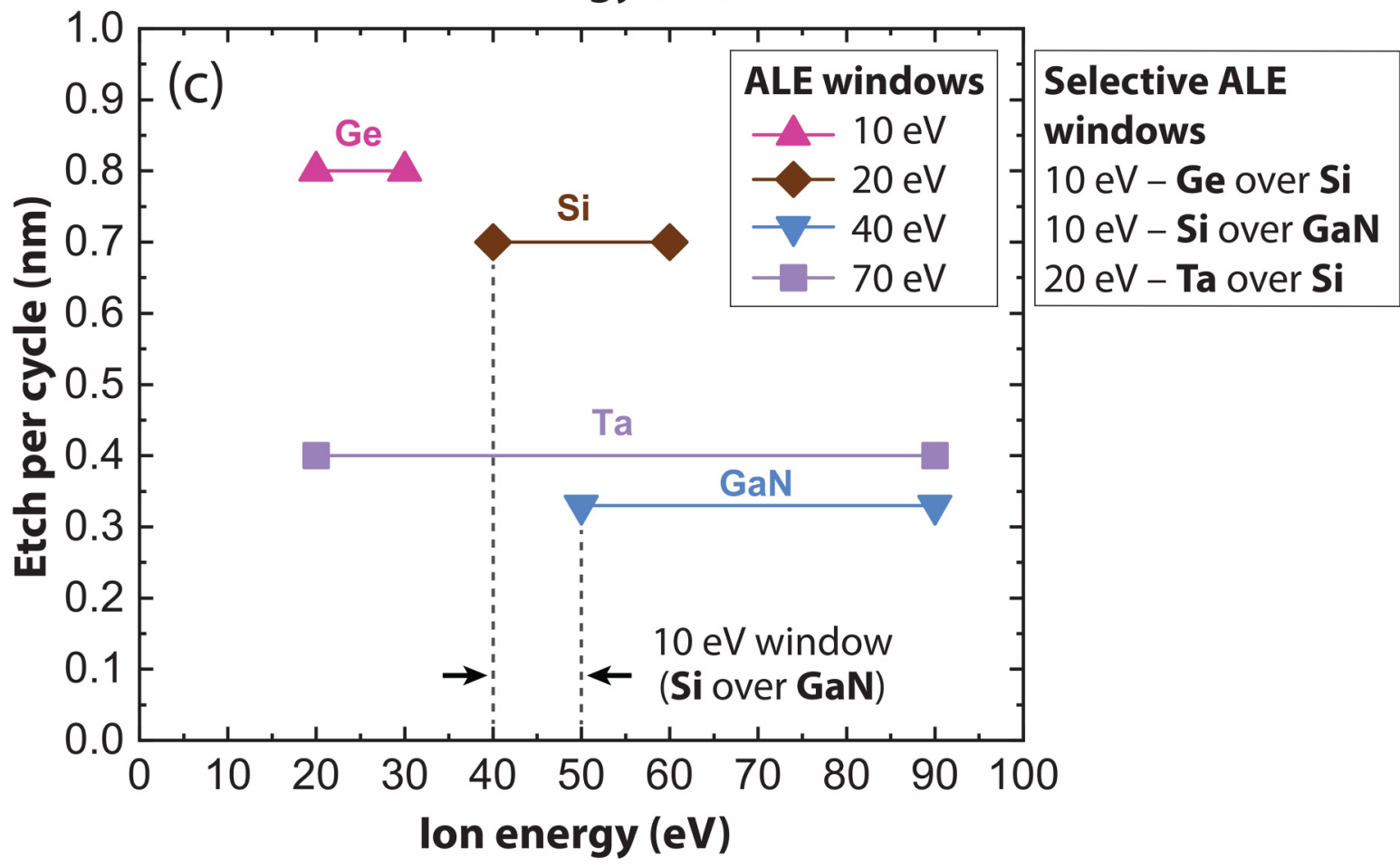

FIG. 1. (a) Schematic representation of the etch per cycle of a target material as a function of the ion energy during anisotropic plasma-enhanced atomic layer etching (ALE). The ALE window and respective sputter etch thresholds are indicated. (b) Schematic representation of the ion flux-energy distribution functions (IFEDFs) for different bias voltage waveforms applied to a substrate during plasma exposure. The area under the curves and hence the ion flux is the same for all IFEDFs. The IFEDFs (shape and FWHM) have been based on data below $100 \mathrm{eV}$ reported in this work and in Ref. 13. (c) ALE windows (in eVs) of different materials shown in a plot of the etch per cycle vs the ion energy. Hypothetical examples of selectivity windows (in eVs) for the ALE of one material with respect to another are also indicated for the same $\mathrm{Cl}_{2}$ plasma-based surface modification. Adapted using data from Refs. 3 and 13. 
type of material removal is known as physical sputtering for which the threshold [Fig. 1(a)] is approximately a factor of 5 to 10 higher than the binding energy ( 2 to $12 \mathrm{eV}$ ) of a material, ${ }^{5,9,10}$ since the energy delivered by an impinging ion gets dissipated in a collision cascade. ${ }^{3,10,11}$ Therefore, etch control with atomic scale precision requires the impinging ion flux to have a well-defined energy lying between the chemical and physical sputter etch thresholds of a target material [Figs. 1(a) and 1(b)]. Data on such ALE windows for the same ALE chemistry recently reported by Kanarik et al. are given in Fig. 1(c). ${ }^{12}$ For example, anisotropic plasma ALE of Ge (using a $\mathrm{Cl}_{2}$ plasma for surface modification) has been reported to have an ALE window of only $10 \mathrm{eV}$ in width and a physical sputter etch threshold of $30 \mathrm{eV} .^{12}$ These low values exemplify the need for precise control over the energy distribution of ions during anisotropic plasma ALE.

In a typical remote, inductively coupled plasma (ICP) etching system, the ion energy has been traditionally controlled by applying a radio-frequency (RF: $13.56 \mathrm{MHz}$ ) sinusoidal bias voltage waveform to the substrate undergoing plasma exposure. ${ }^{7}$ However, this generates a time-varying plasma sheath that is known to yield ion fluxes having broad and bimodal energy distributions [Fig. 1(b)]. ${ }^{14,15}$ Therefore, the ions impinging on a material surface have a range of energies instead of a single value. Such ions can lead to undesired scenarios; for instance, the ion energy exceeding the physical sputter etch threshold of a target material results in a contribution of a physical sputter etching component and consequently, compromised etch control. Furthermore, the use of high frequency RF bias voltages often entails electron heating mechanisms that do not allow for controlling the ion energy independent of the ion flux. ${ }^{16-19}$ This calls for the use of low-frequency ( $\mathrm{LF}: \mathrm{kHz}$ ) bias voltages, which, however, yield ion fluxes with even broader energy distributions when the bias waveform remains sinusoidal [Fig. 1(b)]. ${ }^{13}$

The ability to selectively remove one material with respect to another is an additional requirement for anisotropic plasma ALE. ${ }^{3,4,20}$ Consequently, there also exists a selectivity window in terms of the ion energy for removing only the targeted material by anisotropic plasma ALE, as listed in Fig. 1(c) for hypothetical examples. ${ }^{12}$ For instance, the lower limit of the ALE window for $\mathrm{Si}$ is observed to be at $40 \mathrm{eV}$, while that for $\mathrm{GaN}$ occurs at $50 \mathrm{eV}$. ${ }^{12}$ Selective removal of $\mathrm{Si}$ with respect to $\mathrm{GaN}$ by anisotropic plasma ALE, therefore, requires the incident ions to have an energy distribution lying within a narrow window of only $10 \mathrm{eV}$. Such a narrow energy window again illustrates the need for precise ion energy control that simply cannot be achieved when using RF sinusoidal waveform biasing.

Applying a specific tailored (i.e., non-sinusoidal) voltage waveform on a dielectric substrate has been reported to generate a timeindependent sheath voltage that can yield ions with a narrow, mono-modal energy distribution [Fig. 1(b)]. Wang and Wendt ${ }^{22}$ were the first to demonstrate tailored waveform biasing based on which similar results were also reported by Kudlacek et al. ${ }^{21}$ Both studies reported measurements of the time-independent sheath voltages using home-built equipment in laboratory scale remote plasma reactors. ${ }^{21,22}$ Only simulated ion flux-energy distribution functions (IFEDFs) were reported for dielectric substrates. ${ }^{21,22}$ Tailored waveform biasing in parallel plate capacitively coupled plasma (CCP) reactors has also been reported by other groups. ${ }^{23,24}$
In such reactors where the bias voltage sustains the plasma, ion energy control was performed using the electrical asymmetry effect, which has been reviewed in detail by Economou. ${ }^{25}$ Precise ion energy control with tailored waveform biasing is yet to be employed in the field of atomic scale processing.

In this work, we report on accurate control of the ion energy, independent of the ion flux, by means of LF $(100 \mathrm{kHz})$ tailored bias voltage waveforms applied on dielectric substrates. Precise ion energy control was demonstrated using an industrial scale $(200 \mathrm{~mm})$ commercial remote ICP FlexAL reactor from Oxford Instruments retrofitted with a prototype LF tailored voltage waveform generator from Prodrive Technologies B.V. The technique was used to etch dielectric thin films on planar and 3D substrates to demonstrate its applicability in materials processing. The results of this work report direct measurements of well-defined IFEDFs on dielectric substrates generated with LF tailored waveform biasing.

\section{EXPERIMENTAL SETUP}

\section{A. Setup}

Figure 2 shows a schematic of the Oxford Instruments FlexAL system used for conducting all the experiments in this work. A base pressure in the reactor chamber of $\sim 10^{-6}$ Torr was obtained using a turbo pump. A butterfly valve in front of the turbo pump controlled the effective pumping speed and functioned as an automated pressure controller (APC). A remote inductively coupled

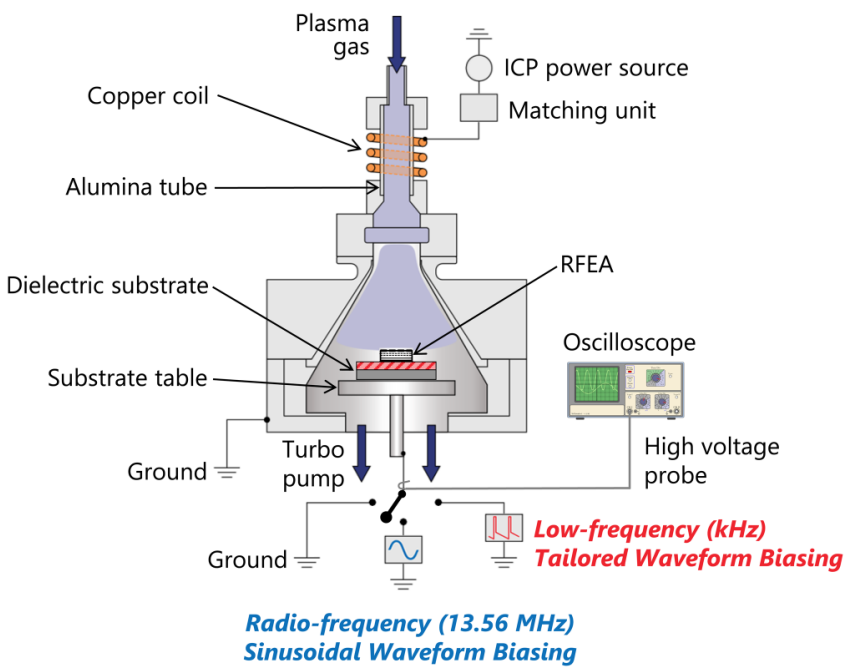

FIG. 2. Schematic of the Oxford Instruments FlexAL system equipped with substrate biasing. During plasma exposure, a substrate placed on the substrate table can be grounded or biased using two configurations-either using RF sinusoidal waveform biasing or using low-frequency (LF: $100 \mathrm{kHz}$ ) tailored waveform biasing. An oscilloscope connected via a high-voltage probe to the substrate table allowed measurement of instantaneous bias voltage waveforms developing on the substrate. A gridded retarding field energy analyzer (RFEA) mounted on top of dielectric substrates ( $\mathrm{Si}$ wafer with $450 \mathrm{~nm}$ thermal $\mathrm{SiO}_{2}$ surface layer) allowed measurement of ion flux-energy distribution functions (IFEDFs) during plasma exposure. 
plasma (ICP) was used with Ar as the plasma gas. The plasma was generated by flowing $25 \mathrm{SCCM}$ of Ar gas through the dielectric alumina tube and applying a radio-frequency (RF: $13.56 \mathrm{MHz}$ ) power of $200 \mathrm{~W}$ to the copper coil that was wrapped around the dielectric tube. The APC valve was kept fully open (at $90^{\circ}$ ), leading to a low chamber pressure of about 3 mTorr during plasma exposure, which can be considered to yield collisionless plasma sheaths. ${ }^{15}$

An additional external RF power supply $(13.56 \mathrm{MHz}$, up to $100 \mathrm{~W}$ ) was connected to the substrate table that allowed RF sinusoidal waveform biasing experiments to be conducted during $\mathrm{Ar}$ plasma exposure. Both RF power sources were in phase with each other and connected to the system via automated matching units (AMUs) consisting of inductive and capacitive components. When experiments with tailored waveform biasing were performed in the FlexAL system, the RF sinusoidal waveform bias generator and its AMU were disconnected from the substrate table. Subsequently, a prototype low-frequency (LF: $100 \mathrm{kHz}$ ) tailored voltage waveform generator, designed and built by Prodrive Technologies B.V., was retrofitted to the substrate table of the FlexAL system. The prototype LF tailored voltage waveform generator consisted of compact power electronics components and did not make use of the bulky coil inductors and vane/vacuum capacitors found in the AMU of the RF sinusoidal waveform biasing equipment.

\section{B. Sputter etching on planar substrates}

The substrates used for physical sputter etching experiments were single side polished (SSP) c-Si (100) wafers having a thick $(\sim 450 \mathrm{~nm})$ thermal oxide layer (i.e., $\left.\mathrm{SiO}_{2}\right)$. The film thicknesses of the $\mathrm{SiO}_{2}$ layers before and after physical sputter etching using $\mathrm{Ar}$ ions were measured by means of an in situ spectroscopic ellipsometer (SE) from J.A. Woollam Co. The optical model used for the SE measurements consisted of a $\mathrm{Si}$ substrate and a thermal $\mathrm{SiO}_{2}$ layer parameterized with a Cauchy dispersion relation. ${ }^{26}$ A sputter etch time of $10 \mathrm{~min}$ was used for each ion energy. The measurements were repeated several times to check for reproducibility.

\section{Ion flux and ion energy measurement}

A commercial, gridded retarding field energy analyzer (RFEA, Semion) from Impedans Ltd. was used to measure IFEDFs. The RFEA was placed on top of the dielectric $\mathrm{SiO}_{2}$ substrates investigated in this work. The RFEA was capable of measuring the timeaveraged surface potential of the dielectric $\mathrm{SiO}_{2}$ substrates biased with RF sinusoidal or LF tailored voltage waveforms. This feature of the RFEA enabled accurate measurement of the IFEDFs on dielectric $\mathrm{SiO}_{2}$ substrates during Ar plasma exposure with substrate biasing. The RFEA had a resolution of $1 \mathrm{eV}$ for measuring ion energies. Therefore, the data on full-width-at-half-maximum (FWHM) of IFEDFs reported in this work have a measurement uncertainty of $\pm 1 \mathrm{eV}$. The ion flux was calculated using the effective grid transmission factor reported in the literature for an RFEA consisting of four grids (50\% ion transmission for each grid) terminated by a collector plate. ${ }^{27,28}$ The ion flux values reported in this work were assigned an uncertainty of $\pm 23 \%$ in line with the uncertainty reported in the literature for the ion flux measured using such a gridded RFEA. ${ }^{15,27-29}$

\section{Sputter yield calculation}

The sputter yields of $\mathrm{SiO}_{2}$ were calculated using the formula $S=z \rho / \Gamma_{i}$, where $S$ is the sputter yield (atoms/ions), $z$ is the etch rate $(\mathrm{m} / \mathrm{s}), \rho$ is the atomic density $\left(\right.$ atoms $\left./ \mathrm{m}^{3}\right)$, and $\Gamma_{i}$ is the ion flux (ions $/ \mathrm{m}^{2} \mathrm{~s}$ ). ${ }^{30}$ The atomic density of $\mathrm{SiO}_{2}$ was calculated using a mass density of $2.2 \mathrm{~g} / \mathrm{cm}^{3}$ and a mean atom mass of $20.03 \mathrm{u}^{31}$ The etch rate was calculated using the formula $z=\Delta d / t$, where $\Delta d$ is the change in film thickness (m) after sputter etching and $t$ is the sputter etch time (s). Any $z$ values reported below zero likely arise from surface roughening by impinging ions. The uncertainty in $\Delta d$ was obtained from the error in film thickness measurements $(0.02 \mathrm{~nm})$ when using the spectroscopic ellipsometer. The uncertainty in the ion energy values used to determine $z$ was based on the energy spread measured for the FWHM of IFEDFs. The uncertainty in $t$ was assigned a value of $4 \mathrm{~s}$ considering human error in starting and stopping the plasma step for sputter etching. These values were used to calculate the uncertainties (or error bars in graphs) for $S$ and $z$, respectively.

\section{E. Sputter etching on 3D substrates}

$3 \mathrm{D}$ trench nanostructures (width $\sim 100 \mathrm{~nm}$, height $\sim 450 \mathrm{~nm}$, $\mathrm{AR}=4.5: 1)$ were analyzed by cross-sectional transmission electron microscopy (TEM) using a JEOL ARM 200F scanning TEM equipped with a $100 \mathrm{~mm}^{2}$ SDD Energy Dispersive $\mathrm{x}$-ray Spectroscopy (EDX) detector. These 3D nanostructures were created by first depositing a thick $\mathrm{SiO}_{2}$ film on a $\mathrm{Si}$ wafer using PECVD which was subsequently etched into trench structures. ${ }^{32}$ The $\mathrm{SiO}_{2}$ trench structures were then coated with a $\mathrm{SiN}_{x}$ layer using high-temperature $\mathrm{CVD}$, on which a $5 \mathrm{~nm} \mathrm{SiO}_{2}$ layer was deposited using ALD. Coupons containing these trench nanostructures were prepared and provided by Lam Research. Two samples for cross-sectional TEM bright-field imaging were prepared from these trench coupons, one with an as-deposited $\mathrm{SiO}_{2}$ layer and one after the $\mathrm{SiO}_{2}$ layer underwent a 60 min physical sputter etch step using energetic $(100 \pm 3 \mathrm{eV})$ Ar ions generated by LF tailored waveform biasing. The samples consisted of a thin lamella $(\sim 100 \mathrm{~nm})$ prepared by a focused ion beam (FIB) using standard lift-out preparation procedures. The sample used for TEM imaging after sputter etching was coated with a layer of spin-on epoxy (i.e., carbon) to fill the gaps in the trenches in order to protect the outermost layer from curtaining damage during sample preparation by FIB milling. The bright, circular patches observed near the bottom of this image are an artefact of the spin-on epoxy fill. To prevent this artefact, the sample used for TEM imaging the as-deposited 3D substrate was filled with an alternate protective coating of platinum formed by electron beam induced deposition (EBID) prior to FIB milling. Scanning TEM combined with EDX was used to study the chemical composition of the materials in the trench nanostructures.

\section{RESULTS AND DISCUSSION}

Figures 3(a) and 3(b) show how the use of RF sinusoidal voltage waveforms for substrate biasing in a collisionless $\mathrm{Ar}$ plasma generated broad, bi-modal IFEDFs. On the other hand, the application of LF tailored voltage waveforms resulted in 

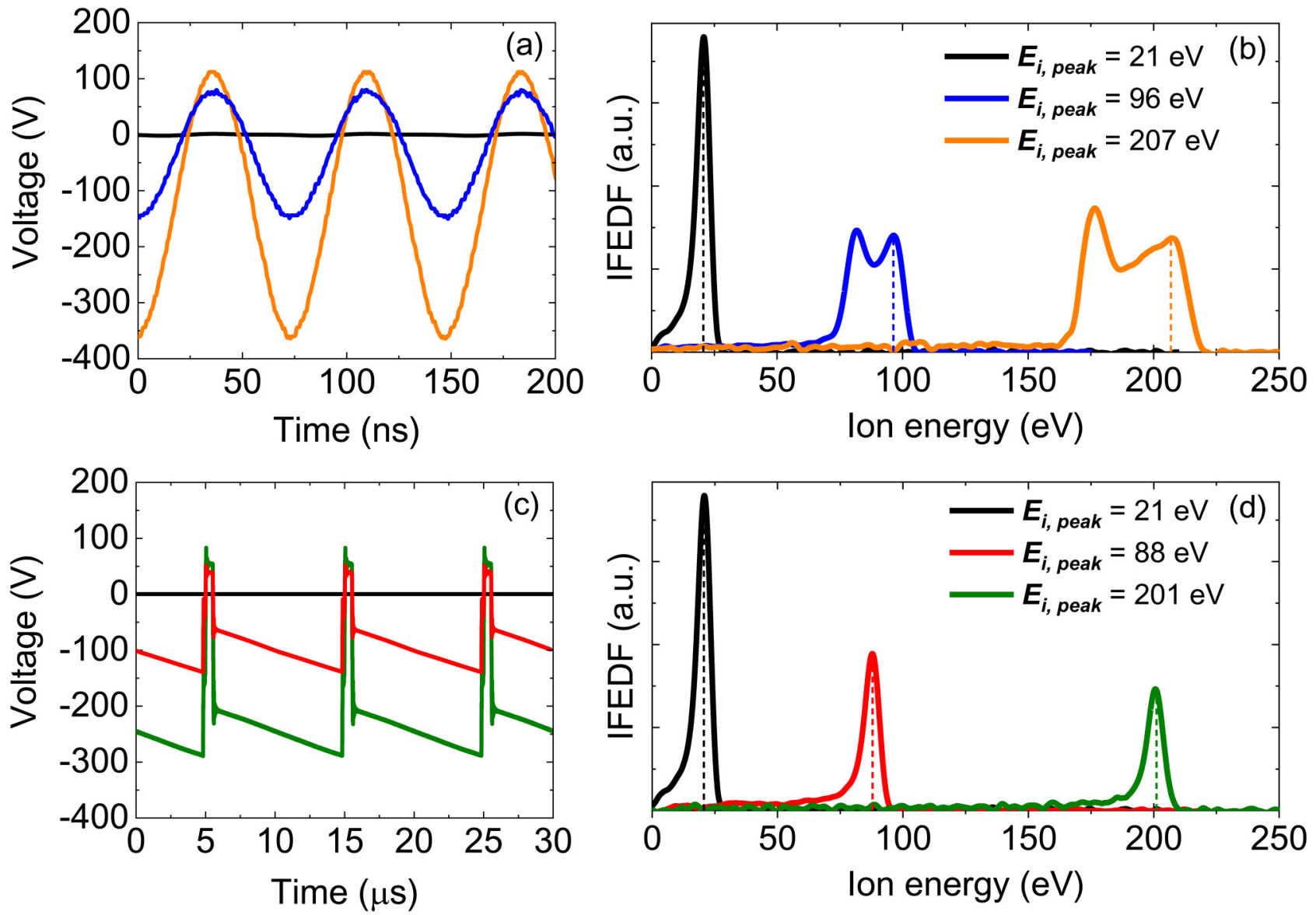

FIG. 3. (a) and (c) Substrate voltage as a function of time and (b) and (d) ion flux-energy distribution functions (IFEDFs) for grounded and biased $\mathrm{SiO}_{2}$ substrates in an Ar plasma generated using $200 \mathrm{~W}$ remote plasma source power and $3 \mathrm{mTorr}$ pressure. Substrate biasing was performed using (a) and (b) radio-frequency (13.56 MHz) sinusoidal voltage waveforms with varying amplitudes and (c) and (d) low-frequency (100 kHz) tailored voltage waveforms with varying voltage pulse amplitudes at a constant voltage ramp. The legends provide values for the ion energy at the peak of the IFEDFs, $\boldsymbol{E}_{i, \text { peak }}$ (indicated by dashed lines).

narrow, mono-modal IFEDFs [Figs. 3(c) and 3(d)]. The tailored waveform consisted of a time-varying negative voltage (i.e., a linear voltage ramp) followed by a positive voltage pulse. When substrates with dielectric surface layers (e.g., Si wafers with a $450 \mathrm{~nm}$ thermal $\mathrm{SiO}_{2}$ used in this work) are biased using LF tailored voltage waveforms, the slope of the negative voltage ramp needs to be optimized to compensate the rate of surface charging due to positive ion impingement. ${ }^{21,22}$ The sheath voltage remains constant under this condition yielding a narrow, mono-modal IFEDF. The subsequent positive voltage pulse attracts electrons toward the substrate which then discharge the surface. The measured FWHM of the IFEDFs on dielectric substrates biased using tailored voltage waveforms was about 6 or $7 \pm 1 \mathrm{eV}$, as shown in Fig. 4(a). This is comparable to the FWHM of $6 \pm 1 \mathrm{eV}$ for the mono-modal IFEDF measured on a grounded substrate. Such mono-modal IFEDFs are typically reported for a grounded substrate exposed to an inductively coupled discharge, where the IFEDFs can have an FWHM of up to about $10 \mathrm{eV}$ (depending on pressure, parasitic capacitance, etc.). ${ }^{13,15,33}$ The obtained results demonstrate how LF tailored waveform biasing generates a flux of ions with a low energy spread, thereby enabling precise ion energy control.

The ion energy could be enhanced for both RF sinusoidal and LF tailored waveform biasing by increasing the amplitude of the respective voltage waveforms. The FWHM of IFEDFs for RF biased substrates increased linearly with the bias voltage amplitude, whereas the FWHM for LF tailored waveform biasing remained at $7 \pm 1 \mathrm{eV}$ [Fig. 4(a)]. This value lies well within the narrow ALE windows of, for example, 10 and $20 \mathrm{eV}$ for Ge and Si [Fig. 1(b)], ${ }^{12}$ respectively. Such narrow IFEDFs ensure that the ion flux impinging on a surface is efficiently utilized for complete removal of only the modified surface layer [i.e., no incomplete or bulk etching components, Fig. 1(a)], thereby enabling both self-limiting surface reactions and a higher throughput for ALE. ${ }^{3,10,34}$ In addition, the $7 \pm 1 \mathrm{eV}$ wide IFEDFs could potentially enable new selective anisotropic plasma ALE processes by exploiting narrow selectivity 

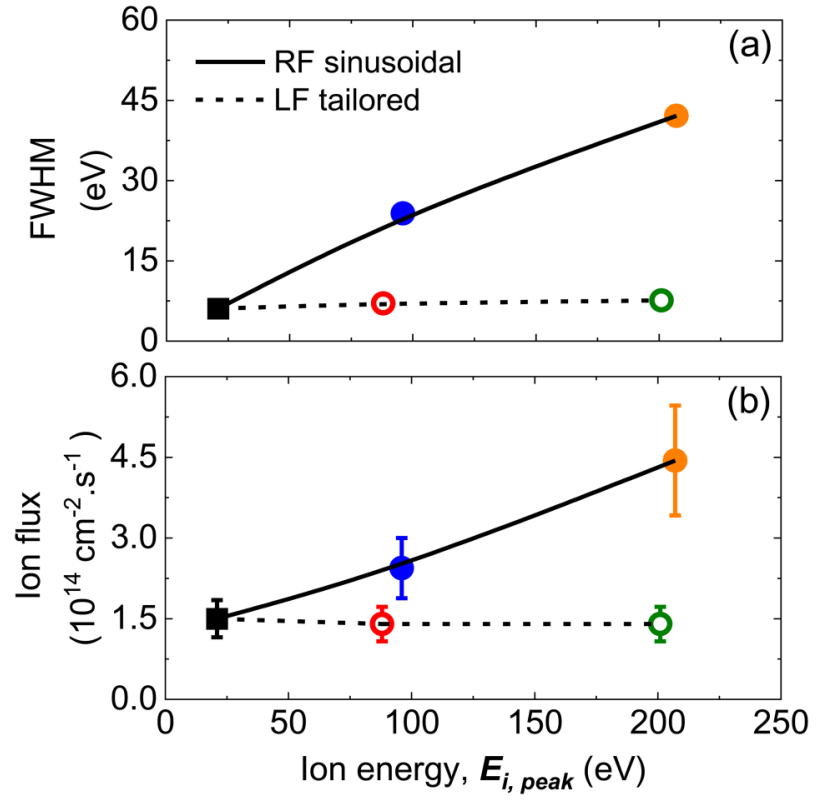

FIG. 4. (a) Full-width-at-half-maximum (FWHM) and (b) total ion flux for ion flux-energy distribution functions (IFEDFs) in Figs. 3(b) and 3(d) expressed as a function of the ion energy at the peak of the IFEDFs, $E_{i, p e a k}$. The lines serve as a guide to the eye.

windows [e.g., $10 \mathrm{eV}$ selective ALE window of $\mathrm{Si}$ with respect to GaN, Fig. 1(b)]. ${ }^{12}$

It has been reported that substrate biasing using RF sinusoidal voltage waveforms generate rapidly oscillating plasma sheaths, which can cause electron heating. ${ }^{16-19}$ Such electron heating mechanisms can influence the plasma properties (e.g., mean electron temperature, plasma density), which, in turn, can cause the ion flux to vary as a function of the ion energy, as shown in Fig. 4(b). ${ }^{16-19}$ The LF tailored bias voltage waveforms used in this work did not cause any electron heating, demonstrating ion energy control independent of the ion flux [Fig. 4(b)].

To implement LF tailored waveform biasing in materials processing, energetic Ar ions obtained with this technique were used to etch thin films of thermal $\mathrm{SiO}_{2}$ by physical sputtering. The etch rates were determined from the change in film thickness as measured by in situ SE. Physical sputter yields calculated from these etch rates are shown in Fig. 5 and compared to values reported in the literature. ${ }^{30,31,35-49}$ The figure illustrates that sputter yields for $\mathrm{SiO}_{2}$ have been frequently reported in the literature at high ion energies $(\gg 100 \mathrm{eV})$ where there is fairly good agreement between the different datasets. However, experimental data on sputter yields at low energies $(<100 \mathrm{eV})$ near the sputter etch threshold are comparatively less abundant. The results of this work demonstrate that ions with narrow IFEDFs generated by LF tailored waveform biasing can be used to obtain accurate experimental data on physical sputter yields at low ion energies. Furthermore, physical sputter etch thresholds are generally reported in the literature by extrapolating the physical sputter yields measured at high ion energies to the low energy range using empirical models. ${ }^{11}$ Any variations in fitting parameters of the empirical models used during extrapolation consequently lead to variations in the values of the extrapolated thresholds. For instance, the physical sputter etch threshold of $\mathrm{SiO}_{2}$ has been reported to range between 30 and $50 \mathrm{eV} .^{31}$ In this work, a physical sputter etch threshold of $36 \pm 2 \mathrm{eV}$ for $\mathrm{SiO}_{2}$ was determined from a plot of the sputter etch rates below $100 \mathrm{eV}$ measured as a function of the ion energy (Fig. 5, inset). This result demonstrates that experimental data on physical sputter etch

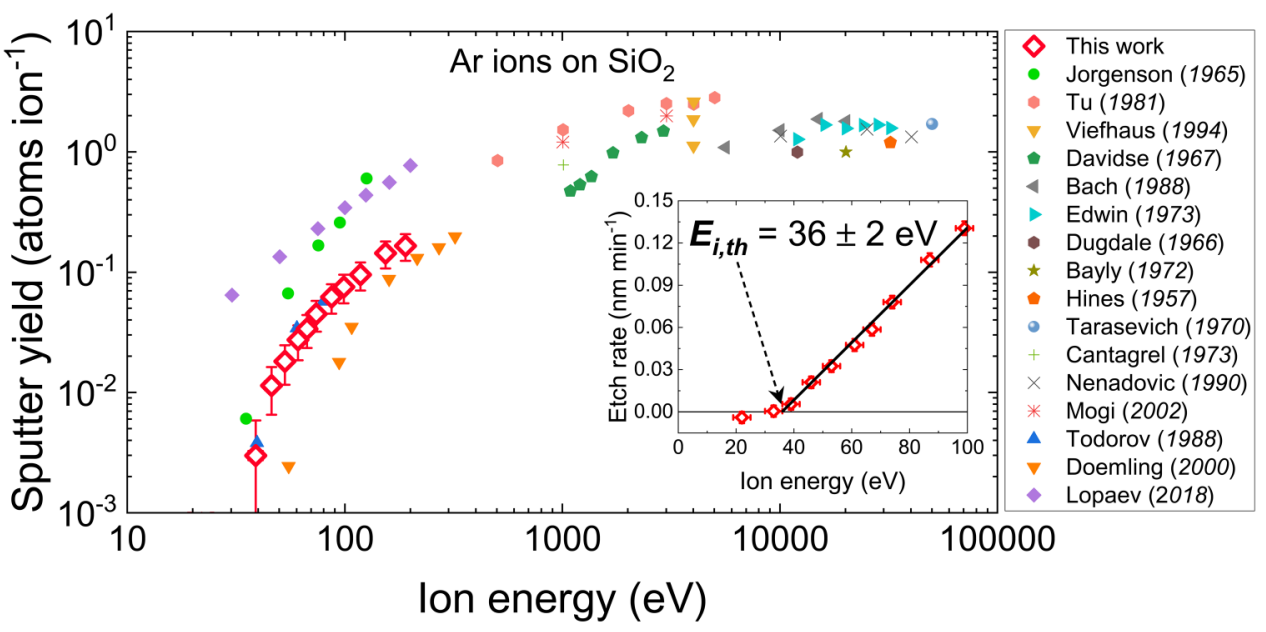

FIG. 5. Physical sputter yields of $\mathrm{SiO}_{2}$ using Ar ions reported in this work and in the literature. ${ }^{30,31,35-49}$ The ion flux-energy distribution functions (IFEDFs) were generated by applying low-frequency tailored waveform biasing to substrates exposed to an Ar plasma at $200 \mathrm{~W}$ remote plasma source power and $3 \mathrm{mTorr}$ pressure. The inset shows the physical sputter etch rate of $\mathrm{SiO}_{2}$ as a function of the ion energy. Etch rates above zero were fitted using a straight line after which the physical sputter etch threshold, $E_{i, t h}$, of $\mathrm{SiO}_{2}$ was determined from the horizontal intercept of the fitted line. 


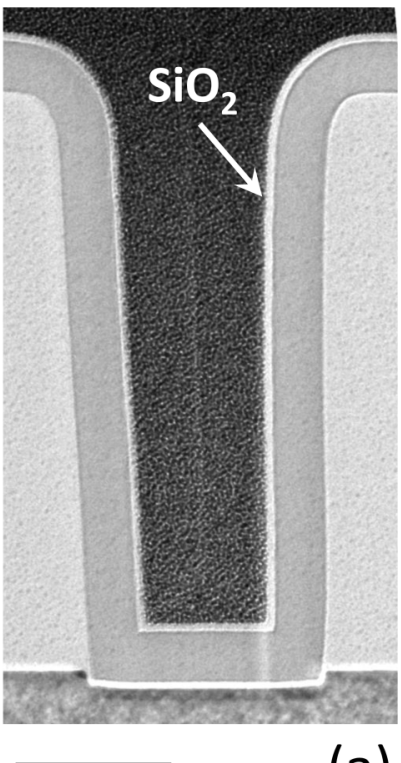

$100 \mathrm{~nm}$ (a)

\section{$100 \mathrm{~nm}$}

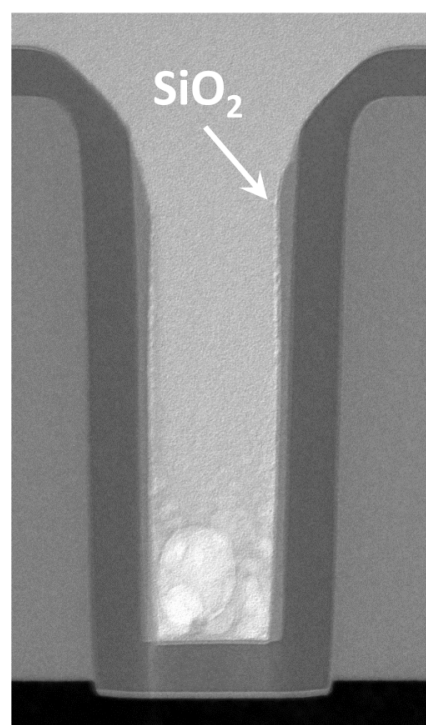

(b)

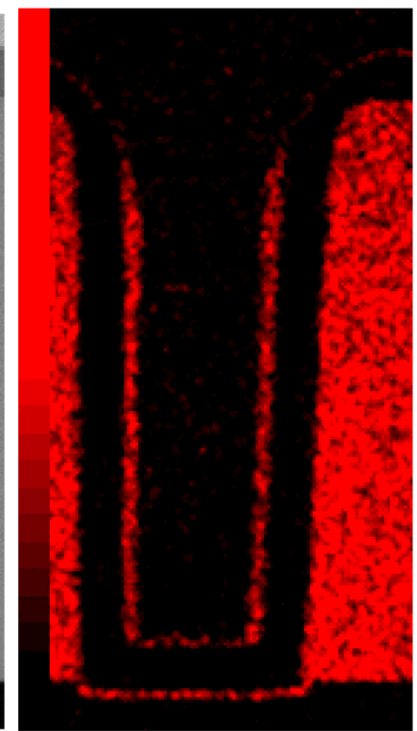

(c)

FIG. 6. Cross-sectional transmission electron microscopy (TEM) images of $3 \mathrm{D}$ trench nanostructures (aspect ratio 4.5:1), where the outermost layer consists of a $\mathrm{SiO}_{2}$ thin film (a) as-deposited and (b) after physical sputter etching using $100 \pm 3 \mathrm{eV}$ ions generated by applying low-frequency (100 $\mathrm{kHz}$ ) tailored waveform biasing to the substrate in an Ar plasma at $200 \mathrm{~W}$ remote plasma source power and 3 mTorr pressure. (c) Energy dispersive x-ray (EDX) mapping of oxygen for the TEM image shown in (b).

thresholds can be obtained using LF tailored waveform biasing. Such data can, for example, be used to delineate the upper ion energy limit of ALE windows (Fig. 1), which is a prerequisite for designing novel anisotropic plasma ALE chemistries.

Anisotropic plasma etching by means of LF tailored waveform biasing was also investigated on a three-dimensional (3D) substrate that consisted of trench nanostructures (aspect ratio 4.5:1) having a $\sim 5 \mathrm{~nm}$ thick outermost layer of $\mathrm{SiO}_{2}$ as shown in Fig. 6(a). This 3D substrate was exposed to a collisionless Ar plasma where the energy of directional ions was enhanced to $100 \pm 3 \mathrm{eV}$ (i.e., well beyond the physical sputter etch threshold of $\mathrm{SiO}_{2}$ ) with $\mathrm{LF}$ tailored waveform biasing. The energetic and directional ion bombardment led to physical sputter etching of the ALD-prepared $\mathrm{SiO}_{2}$ only from the horizontal trench surfaces at an etch rate of $\sim 0.05 \mathrm{~nm} / \mathrm{min}$. This caused the $\mathrm{SiO}_{2}$ layer thickness to decrease to $\sim 2 \mathrm{~nm}$ only at the horizontal top and bottom regions of the trench [Figs. 6(b) and 6(c)]. Note that the etch rate of the thermal $\mathrm{SiO}_{2}$ on a blanket wafer (Fig. 5) had a comparatively higher value of $\sim 0.13 \mathrm{~nm} / \mathrm{min}$ for the same ion energy. The thickness of the $\mathrm{SiO}_{2}$ layer was observed to locally increase at the vertical sidewalls at the top $(\sim 11 \mathrm{~nm})$ and bottom $(\sim 9 \mathrm{~nm})$ regions in Fig. 6(b). It is speculated that this could arise from redeposition of $\mathrm{SiO}_{2}$ on the vertical sidewalls. ${ }^{35}$ The results of Fig. 6 where the $\mathrm{SiO}_{2}$ thickness decreased only at horizontal trench regions effectively demonstrate that mono-energetic ions generated with LF tailored waveform biasing can perform anisotropic etching on 3D substrates. Therefore, LF tailored waveform biasing can be used to conduct anisotropic plasma ALE, which will be investigated in future work.

\section{CONCLUSION}

LF tailored waveform biasing during collisionless plasma exposure enabled precise ion energy control, independent of the ion flux, on dielectric substrates. The use of a prototype LF tailored voltage waveform generator in a remote plasma reactor yielded ions with narrow and mono-modal IFEDFs ( $7 \pm 1 \mathrm{eV}$ FWHM). The capability of this technique to accurately control the ion energy was demonstrated in sputter etching experiments. Using ions with a well-defined energy for physical sputter etching enables experimental measurement of the sputter yields at low energies $(<100 \mathrm{eV})$ and etch thresholds, where the measured thresholds serve as vital input for designing new plasma ALE chemistries. LF tailored waveform biasing was also used to conduct anisotropic plasma etching on 3D substrates. The sputter etching results obtained on planar and 3D substrates demonstrate that this technique can be implemented in materials processing. Tailored waveform biasing offers numerous opportunities for advancing other (selective) atomic scale processing techniques. Ions with low ion energies and narrow IFEDFs may be used for atomic scale cleaning, for example, selective removal of ultrathin native oxide or damaged surface layers with respect to the underlying material. ${ }^{3,10,50,51}$ Mono-energetic ions can also allow for topographically selective deposition on $3 \mathrm{D}$ substrates, ${ }^{52-54}$ which is the deposition counterpart of selective anisotropic etching. Recently, ion energy control during plasma-enhanced atomic layer deposition (ALD) with RF sinusoidal waveform biasing has been demonstrated to enable control over the growth and material properties of thin films. ${ }^{53,55-58}$ Using the 
narrow, mono-modal IFEDFs generated by LF tailored waveform biasing could offer even better control over the growth and properties. Further investigation on the different aspects of tailored waveforms (e.g., frequency, pulse duty cycle, etc.), IFEDFs in reactive molecular plasmas, and atomic scale processing with LF tailored waveform biasing will be reported in future publications.

\section{SUPPLEMENTARY MATERIAL}

See the supplementary material for datasets corresponding to the ion flux-energy distribution functions (IFEDFs) shown in Figs. 3(b) and 3(d).

\section{ACKNOWLEDGMENTS}

The authors would like to thank Cristian van Helvoirt, Jeroen van Gerwen, Martijn Dijstelbloem, and Barathi Krishnamoorthy for their invaluable contribution in setting up the equipment used in this work. Qihao Yu and Jan Buiter are acknowledged for their assistance during experiments, Dr. Harm Knoops and Karsten Arts for useful discussions, and Dr. Alfredo Mameli for data analysis. Dr. Dennis Hausmann (Lam Research) is acknowledged for providing the 3D trench nanostructures. This work is part of the research program HTSM with Project No. 17124, which is financed by the Netherlands Organization for Scientific Research (NWO).

\section{DATA AVAILABILITY}

The data that support the findings of this study are openly available in 4TU. Research Data at https://data.4tu.nl/, Ref. 59.

\section{REFERENCES}

${ }^{1}$ S. Salahuddin, K. Ni, and S. Datta, Nat. Electron. 1, 442 (2018).

${ }^{2}$ R. Clark, K. Tapily, K. Yu, T. Hakamata, S. Consiglio, D. O’Meara, C. Wajda, J. Smith, and G. Leusink, APL Mater. 6, 058203 (2018).

${ }^{3}$ K. J. Kanarik, S. Tan, and R. A. Gottscho, J. Phys. Chem. Lett. 9, 4814 (2018).

${ }^{4}$ T. Faraz, F. Roozeboom, H. C. M. Knoops, and W. M. M. Kessels, ECS J. Solid State Sci. Technol. 4, N5023 (2015).

${ }^{\mathbf{5}}$ M. A. Lieberman and A. J. Lichtenberg, Principles of Plasma Discharges and Materials Processing, 2nd ed. (John Wiley \& Sons, Hoboken, NJ, 2005).

${ }^{6}$ K. J. Kanarik, T. Lill, E. A. Hudson, S. Sriraman, S. Tan, J. Marks, V. Vahedi, and R. A. Gottscho, J. Vac. Sci. Technol. A 33, 020802 (2015).

${ }^{7}$ V. M. Donnelly and A. Kornblit, J. Vac. Sci. Technol. A 31, 050825 (2013).

${ }^{8}$ G. S. Oehrlein, D. Metzler, and C. Li, ECS J. Solid State Sci. Technol. 4, N5041 (2015).

${ }^{9}$ M. Nastasi, J. W. Mayer, and J. K. Hirvonen, Ion-Solid Interaction: Fundamental Applications (Cambridge University Press, 1996), pp. 88-114.

${ }^{10}$ I. L. Berry, K. J. Kanarik, T. Lill, S. Tan, V. Vahedi, and R. A. Gottscho, J. Vac. Sci. Technol. A 36, 01B105 (2018).

${ }^{11}$ R. Behrisch and W. Eckstein, Sputtering by Particle Bombardment (Springer, New York, 2007).

${ }^{12}$ K. J. Kanarik, S. Tan, W. Yang, T. Kim, T. Lill, A. Kabansky, E. A. Hudson, T. Ohba, K. Nojiri, J. Yu, R. Wise, I. L. Berry, Y. Pan, J. Marks, and R. A. Gottscho, J. Vac. Sci. Technol. A 35, 05 C302 (2017).

${ }^{13}$ X. V. Qin, Y.-H. Ting, and A. E. Wendt, Plasma Sources Sci. Technol. 19, 065014 (2010).
${ }^{14}$ E. Kawamura, V. Vahedi, M. A. Lieberman, and C. K. Birdsall, Plasma Sources Sci. Technol. 8, R45 (1999).

${ }^{15}$ T. Faraz, K. Arts, S. Karwal, H. C. M. Knoops, and W. M. M. Kessels, Plasma Sources Sci. Technol. 28, 024002 (2019).

${ }^{16}$ M. A. Sobolewski and J. H. Kim, J. Appl. Phys. 102, 113302 (2007).

${ }^{17}$ H. C. Lee, M. H. Lee, and C. W. Chung, Appl. Phys. Lett. 96, 071501 (2010).

${ }^{18}$ H. C. Lee and C. W. Chung, Appl. Phys. Lett. 101, 244104 (2012).

${ }^{19}$ J. Schulze, E. Schüngel, and U. Czarnetzki, Appl. Phys. Lett. 100, 024102 (2012).

${ }^{\mathbf{2 0}}$ S. Tan, W. Yang, K. J. Kanarik, T. Lill, V. Vahedi, J. Marks, and R. A. Gottscho, ECS J. Solid State Sci. Technol. 4, N5010 (2015).

${ }^{21}$ P. Kudlacek, R. F. Rumphorst, and M. C. M. Van De Sanden, J. Appl. Phys. 106, 073303 (2009).

${ }^{22}$ S.-B. Wang and A. E. Wendt, J. Appl. Phys. 88, 643 (2000).

${ }^{23}$ Z. Donkó, J. Schulze, U. Czarnetzki, A. Derzsi, P. Hartmann, I. Korolov, and E. Schüngel, Plasma Phys. Control. Fusion 54, 124003 (2012).

${ }^{24}$ U. Czarnetzki, J. Schulze, E. Schüngel, and Z. Donkó, Plasma Sources Sci. Technol. 20, 024010 (2011).

${ }^{\mathbf{2 5}}$ D. J. Economou, J. Vac. Sci. Technol. A 31, 050823 (2013).

${ }^{26}$ E. Langereis, S. B. S. Heil, H. C. M. Knoops, W. Keuning, M. C. M. van de Sanden, and W. M. M. Kessels, J. Phys. D Appl. Phys. 42, 073001 (2009).

${ }^{27}$ T. Baloniak, R. Reuter, C. Flötgen, and A. Von Keudell, J. Phys. D Appl. Phys. 43, 055203 (2010).

${ }^{28}$ K. Denieffe, C. M. O. Mahony, P. D. Maguire, D. Gahan, and M. B. Hopkins, J. Phys. D Appl. Phys. 44, 075205 (2011).

${ }^{29}$ D. Gahan, B. Dolinaj, and M. B. Hopkins, Plasma Sources Sci. Technol. 17, 035026 (2008).

${ }^{30}$ H. Viefhaus, K. Hennesen, M. Lucas, E. M. Müller-Lorenz, and H. J. Grabke, Surf. Interface Anal. 21, 665 (1994).

${ }^{31}$ D. V. Lopaev, T. V. Rakhimova, A. T. Rakhimov, A. I. Zotovich, S. M. Zyryanov, and M. R. Baklanov, J. Phys. D Appl. Phys. 51, 02LT02 (2018).

${ }^{32}$ T. Faraz, M. van Drunen, H. C. M. Knoops, A. Mallikarjunan, I. Buchanan, D. M. Hausmann, J. Henri, and W. M. M. Kessels, ACS Appl. Mater. Interfaces 9, 1858 (2017).

${ }^{33}$ J. R. Woodworth, I. C. Abraham, M. E. Riley, P. A. Miller, T. W. Hamilton, B. P. Aragon, R. J. Shul, and C. G. Willison, J. Vac. Sci. Technol. A 20, 873 (2002).

${ }^{34}$ T. Lill, K. J. Kanarik, S. Tan, M. Shen, E. Hudson, Y. Pan, J. Marks, V. Vahedi, and R. A. Gottscho, in Encyclopedia of Plasma Technology, edited by J. L. Shohet (CRC Press, Boca Raton, 2016), pp. 133-142.

${ }^{35}$ M. P. Seah and T. S. Nunney, J. Phys. D Appl. Phys. 43, 253001 (2010).

${ }^{36}$ G. V. Jorgenson and G. K. Wehner, J. Appl. Phys. 36, 2672 (1965).

${ }^{37}$ Y. Y. Tu, T. J. Chuang, and H. F. Winters, Phys. Rev. B 23, 823 (1981).

${ }^{38}$ P. D. Davidse and L. I. Maissel, J. Vac. Sci. Technol. 4, 33 (1967).

${ }^{39}$ H. Bach, J. Non Cryst. Solids 102, 36 (1988).

${ }^{40}$ R. P. Edwin, J. Phys. D Appl. Phys. 6, 833 (1973).

${ }^{41}$ R. A. Dugdale and S. D. Ford, Trans. Br. Ceram. Soc. 65, 165 (1966).

${ }^{42}$ A. R. Bayly, J. Mater. Sci. 7, 404 (1972).

${ }^{43}$ R. L. Hines, J. Appl. Phys. 28, 587 (1957).

${ }^{44}$ M. Tarasevich, Appl. Opt. 9, 173 (1970).

${ }^{45}$ M. Cantagrel and M. Marchal, J. Mater. Sci. 8, 1711 (1973).

${ }^{46}$ T. Nenadović, B. Perraillon, Ž Bogdanov, Z. Djordjević, and M. Milić, Nucl. Inst. Methods Phys. Res. B 48, 538 (1990).

${ }^{47}$ K. Mogi, T. Ogiwara, M. Suzuki, and SERD project of SASJ, J. Surf. Anal. 9, 514 (2002).

${ }^{48}$ S. S. Todorov and E. R. Fossum, Appl. Phys. Lett. 52, 365 (1988).

${ }^{49}$ M. F. Doemling, B. Lin, N. R. Rueger, G. S. Oehrlein, R. A. Haring, and Y. H. Lee, J. Vac. Sci. Technol. A Vac. Surf. Film. 18, 232 (2000).

${ }^{50}$ H. C. M. Knoops, T. Faraz, K. Arts, and W. M. M. Kessels, J. Vac. Sci. Technol. A 37, 030902 (2019). 
${ }^{51}$ S. G. Rosenberg, C. Wagenbach, V. R. Anderson, S. D. Johnson, N. Nepal, A. C. Kozen, J. M. Woodward, Z. R. Robinson, M. Munger, H. Joress, K. F. Ludwig, and C. R. Eddy, J. Vac. Sci. Technol. A 37, 020928 (2019).

${ }^{52}$ W.-H. Kim, F. S. Minaye Hashemi, A. J. M. Mackus, J. Singh, Y. Kim, D. Bobb-Semple, Y. Fan, T. Kaufman-Osborn, L. Godet, and S. F. Bent, ACS Nano 10, 4451-4458 (2016).

${ }^{53}$ T. Faraz, H. C. M. Knoops, M. A. Verheijen, C. A. A. van Helvoirt, S. Karwal, A. Sharma, V. Beladiya, A. Szeghalmi, D. M. Hausmann, J. Henri, M. Creatore, and W. M. M. Kessels, ACS Appl. Mater. Interfaces 10, 13158 (2018).

${ }^{54}$ A. Chaker, C. Vallee, V. Pesce, S. Belahcen, R. Vallat, R. Gassilloud, N. Posseme, M. Bonvalot, and A. Bsiesy, Appl. Phys. Lett. 114, 043101 (2019).
${ }^{55}$ H. B. Profijt, M. C. M. van de Sanden, and W. M. M. Kessels, J. Vac. Sci. Technol. A 31, 01 A106 (2013).

${ }^{56}$ S. Karwal, M. A. Verheijen, B. Williams, T. Faraz, W. Kessels, and M. Creatore, J. Mater. Chem. C 6, 3917 (2018)

${ }^{57}$ V. Beladiya, M. Becker, T. Faraz, W. M. M. Kessels, P. Schenk, F. Otto, T. Fritz, M. Gruenewald, C. Helbing, K. D. Jandt, A. Tünnermann, M. Sierka, and A. Szeghalmi, Nanoscale 12, 2089 (2020).

${ }^{58}$ S. Karwal, M. A. Verheijen, K. Arts, T. Faraz, W. M. M. Kessels, and M. Creatore, Plasma Chem. Plasma Process. 40, 697 (2020).

${ }^{\mathbf{5 9}} \mathrm{T}$. Faraz, "Precise ion energy control with tailored waveform biasing for atomic scale processing," 4TU.ResearchData, https://data.4tu.nl/. 